\title{
A System Dynamics Evaluation Model of Avionics Fuel Control System
}

\author{
Zhen Zhao \\ College of Aerospace Automation, Civil Aviation \\ University of China, Tianjin \\ zhenzhao0523@gmail.com \\ Yigang Sun \\ College of Aerospace Automation, Civil Aviation \\ University of China, Tianjin \\ ygsun@cauc.edu.cn
}

\author{
Dexin Zhou \\ College of Aerospace Automation, Civil Aviation \\ University of China, Tianjin \\ dxzhou@cauc.edu.cn \\ Hao Li \\ College of Aerospace Automation, Civil Aviation \\ University of China, Tianjin \\ 1165613606@qq.com
}

\begin{abstract}
Avionics fuel control system, which is applied for delivering fuel to an engine in modern aircraft system, is difficult to study, design, and implement due to the highsecurity measures and the need for standard certification.To evaluate the complex dynamics involved in implementing fuel regulating for aircraft fuel system, a quantifiable evaluation model for avionics fuel control system based on system dynamics theory is developed in this paper. Firstly, the speed and flow regulation process is briefly introduced in an avionics fuel control system. Then, based on these operation principles, the analytic relations among the system state variables are provided, which come into being the system dynamics evaluation model. According to these analytic relations, the evalutation model is realized and simulated using Vensim tool. The simulation result shows that this model can be used efficiently in modeling and evaluating of avionic fuel control system for its clear causality, suitable complexity, and exact describe characteristics.
\end{abstract}

Keywords-Avionics Fuel Control System; Aircraft; System dynamics; Vensim; Modeling and Evaluating

\section{INTRODUCTION}

Fuel is usually the most critical fluid that an avionic system must deal with compared to other aircraft fluids (water, oil, etc.) [1].The fuel injection system, whose working state directly influences the safety and stability of the aero-engine, is the main part of aero-engine [2, 3]. In order to meet the needs of more-electric and all-electric aircraft development, avionics fuel control system integrated with fieldbus technology, electronic control technology, and advanced measurement technology, is used to set up the all-electrical intelligent fuel management system in modern aircraft [4].

Due to the high-security measures and the need for standard certification, avionics fuel control system is difficult to study, design, and implement in modern aircraft system. System dynamics is a convenient and efficient method that can be used to analyze future behavior and development problems of nonlinear, multiple feedback complex systems [5] for its whole life cycle. In this article, system dynamics theory is utilized to build an evaluation model for the avionics fuel control system.

The rest of this paper is organized as follow. In Section II, the principle of an avionics fuel control system is illustrated. Then, a system dynamics evaluation model is built for this avionics fuel control system using Vensim tool in Section III. Section IV gives some simulation results and discussing. Finally, conclusion is drawn in Section V.

\section{AN AVIONICS FUEl CONTROL SySTEM}

Avionics fuel control system has been an essential and significant part of an aero-engine. For an aero-engine, it is necessary to achieve maximum thrust with minimum engine weight, which means that all fuel components operate at corresponding mechanical or thermal limits for at least one of the aero-engine's critical operating conditions. Therefore, the fuel control system must directly or indirectly control each limiting parameter and confine the engine thrust so that none of the limits are exceeded [6]. Maximum power engine operation (maximum engine speed) will, consequently, require operation at one or more of the engine operating limits. Part power engine operation should occur below all limits and at the lowest specific fuel consumption for the thrust requested.

Fig .1 shows the primary structure of a main fuel system. The main avionic fuel system contains tank, fuel switch, centrifugal pump, pressure constant valve, fuel filter, main plunger pump, main fuel regulator, fuel distributor, main and assistant pipe laying, fuel venting valve, drip tank, nozzle, etc..

In this system, the avionic fuel control system contains two main regulators, i.e. speed regulator and flow regulator. Fig .2 and Fig .3 show the control procedure of these two regulators. The operation principle of speed regulator is as below: When the engine is working at a high speed stably; and the position of the throttle lever is fixed, the forces 
acting on the two sides of the distributing valve are equal to each other, which makes the distributing valve remains stable. The feedback valve also stays at the neutral position. The adjuster piston keeps fixed, and the swashplate angle position also remains to the satisfied angle. The oil supplied by the oil pump is consisted with the required oil for engine [7]. When the working condition changes, the speed regulator shows stage characteristic in adjusting the speed of aero-engine. Take throttle lever setting change as an example, it shows rigid feedback stage, flexible feedback stage, and restore equilibrium stage.

By keeping the differential pressure before and after the fuel switch stable, the supplied oil will remain constant under fixed throttle level setting, While the throttle level setting changes, the supplied oil will change consequently.

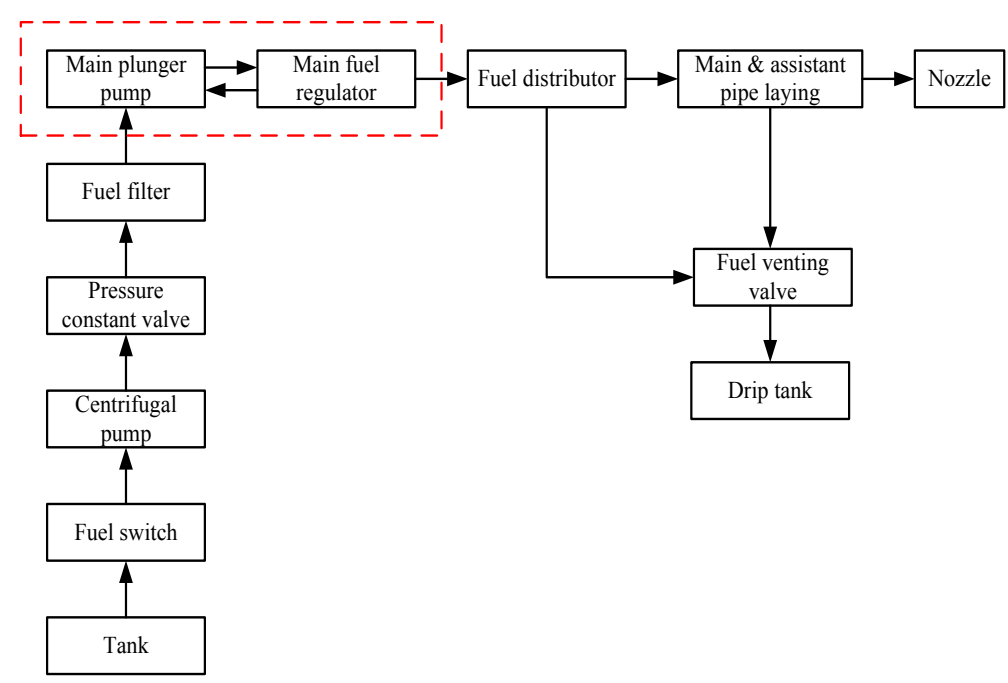

Figure 1. Constitution of a main avionic fuel system

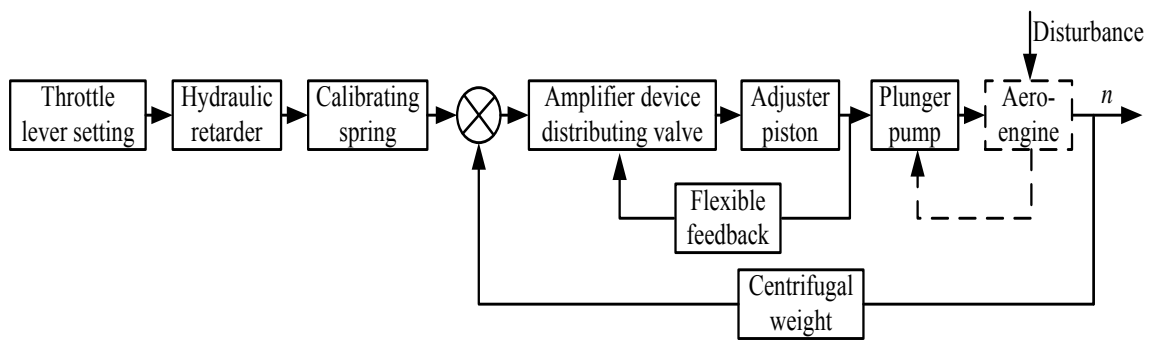

Figure 2. Speed regulator

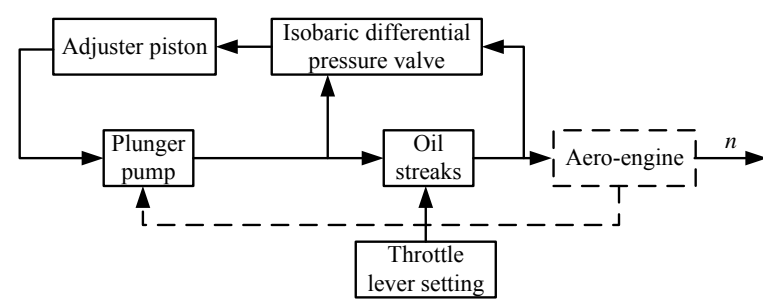

Figure 3. Flow regulator

\section{SYSTEM DYNAMICS EVALUATION MODEL}

The system dynamics evaluation model is to analyze and evaluate how different factors such as flight height, pilot operates, and flight mass, etc. can affect the safety and reliability of flight. To build this model, some assumptions are given as below to simplify the practical avionic fuel control system.

Assumption 1: Base time unit is hour.

Assumption 2: The environment (e.g. temperature, wind, etc.) has no influence on the avionics fuel control system.

The main mathematical relationships of these variables are as below:

$$
\begin{gathered}
d_{1}^{\&}=-4.474 n_{1}-692.8 p_{3}+1462 p_{t 41}-2942 p_{t 45}+22.88 W_{f} \\
\&=-0.024 n_{1}-0.565 n_{2}-41.28 p_{3}+33.02 p_{t 41}+232.1 p_{t 45}+1.715 W_{f} \\
\&=0.752 n_{1}-423 p_{3}+407.1 p_{t 41} \\
p_{t 41}^{\&}=4115 p_{3}-4526 p_{t 41}+52.53 W_{f} \\
\&_{t 45}^{\&}=1.063 n_{1}-269.5 p_{3}+810.1 p_{t 41}-3063 p_{t 45}+11.169 W_{f}
\end{gathered}
$$

$n_{1}$ is low-pressure rotor speed, $n_{2}$ is high-pressure rotor speed, $p_{3}$ is compressor delivery pressure, $p_{t 41}$ is inlet pressure, $p_{t 45}$ is outlet pressure, $W_{f}$ is the fuel supplied by the fuel regulator.

$$
W_{f}=b_{0}-b_{1} \cdot \mathrm{PLA}+b_{2} \cdot \mathrm{PLA}^{2}
$$

PLA is power lever angle operated by the pilot; $b_{0}, b_{1}$, and $b_{2}$ are constant coefficients.

$$
\text { False-PLA }=\frac{-f_{1}+\sqrt{f_{1}^{2}-4 f_{2}\left(n_{1}-f_{0}\right)}}{2 f_{2}}
$$

False-PLA is calculated power lever angle corresponding to practical fuel oil supply; $f_{0}, f_{1}$, and $f_{2}$ are constant coefficients. 


$$
\text { Thrust }=c_{1} n_{1}+c_{2} n_{2}+d_{1} W_{f}
$$

Thrust is thrust acting on a aircraft caused by an aeroengine; $c_{1}, c_{2}$, and $d_{1}$ are constant coefficients.

$$
\text { Resistance }=\frac{1}{2} \rho C_{D} A v^{2}
$$

$\rho$ is the atmosphere density; $C_{D}$ is resistance coefficient; $A$ is windward area of an aircraft; $v$ is the flight speed.

$$
\text { Gravity }=m g
$$

Gravity is gravitational force of an aircraft, $g$ is local acceleration of gravity.

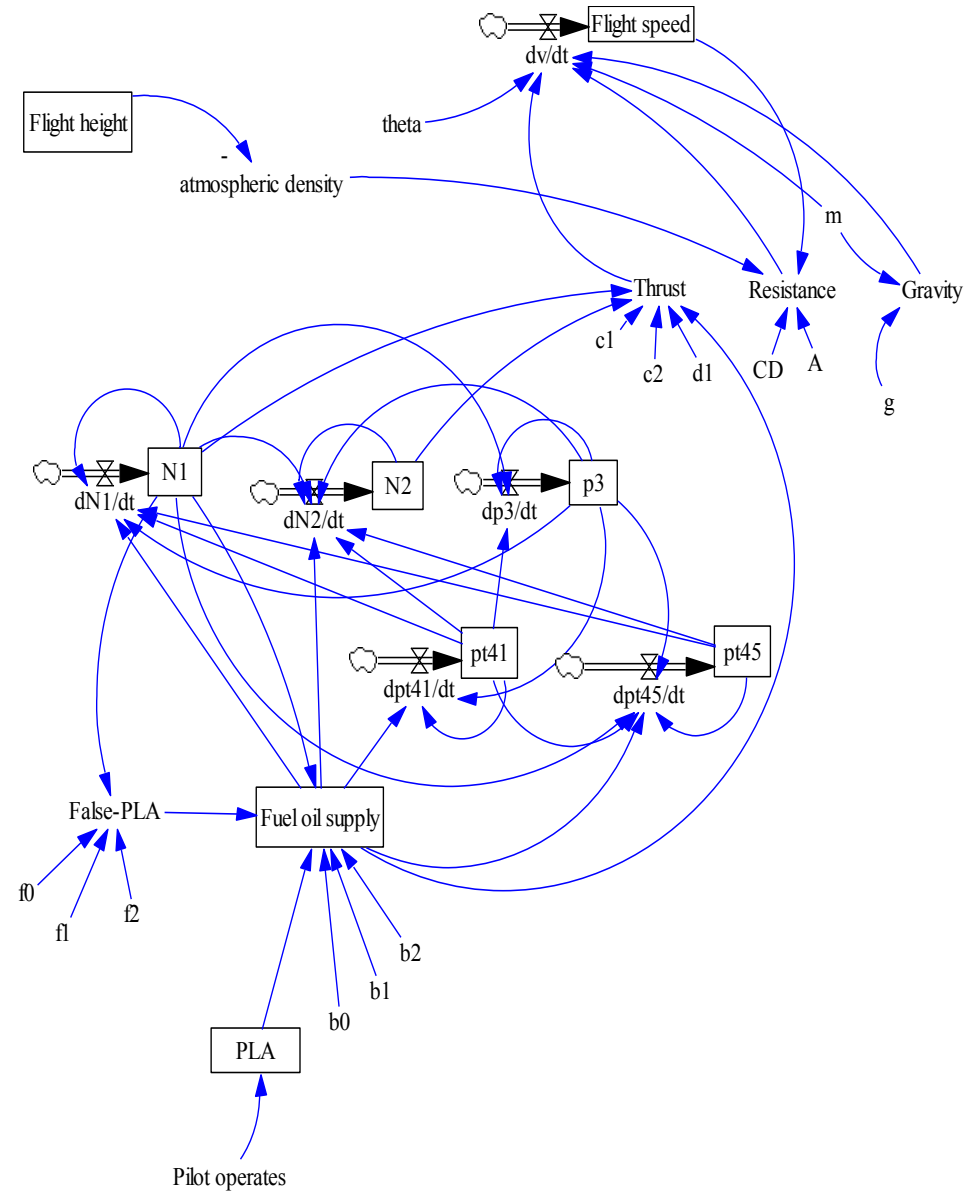

Figure 4. The system dynamics evaluation model

The system dynamics evaluation model in Fig .4 shows the relationship of variables within the avionic fuel control system. The signal ' + ' represents that the independent variable and dependent variable have the same change trends; the signal ' - ' represents that the independent variable and dependent variable have opposite change trend [10].

\begin{tabular}{|c|c|}
\multicolumn{1}{|c|}{ TABLE I MAIN VARIABLES IN THE MODEL } \\
\hline Variable & Description \\
\hline Flight height & The height of the aircraft flying \\
\hline Atmospheric density & $\begin{array}{c}\text { The atmospheric density in the flight } \\
\text { height }\end{array}$ \\
\hline Flight speed & The flight speed of the aircraft \\
\hline Thrust & Engine thrust \\
\hline Resistance & Air resistance \\
\hline Gravity & Low-pressure rotor speed \\
\hline N1 & High-pressure rotor speed \\
\hline $\mathrm{N} 2$ & Compressor delivery pressure \\
\hline $\mathrm{p} 3$ & Inlet pressure \\
\hline $\mathrm{pt} 41$ &
\end{tabular}

\section{SimUlations}

Vensim, which can be used for developing, analyzing, and packaging dynamic feedback models, is simulation software for improving the performance of real complex systems. Vensim [8,9] is utilized to build and simulate the system dynamics evaluation model in this paper. By change parameters, Vensim can give comparison simulation results easily. Furthermore, it can give intuitional cause tree and use tree for state variables in the model. 


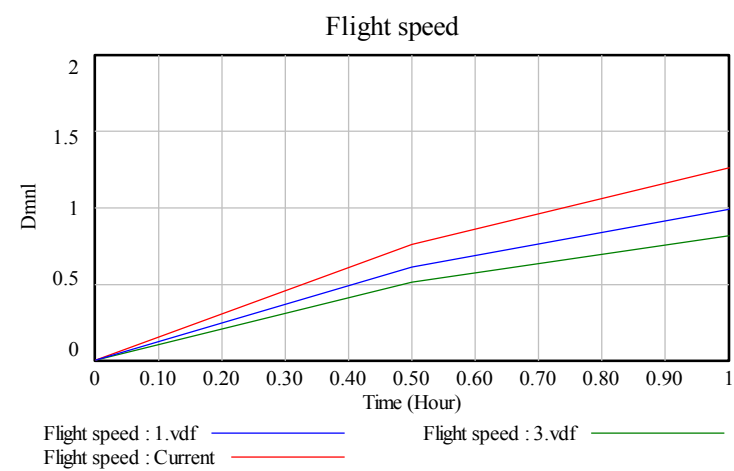

Figure 5. Flight speed with different parameters

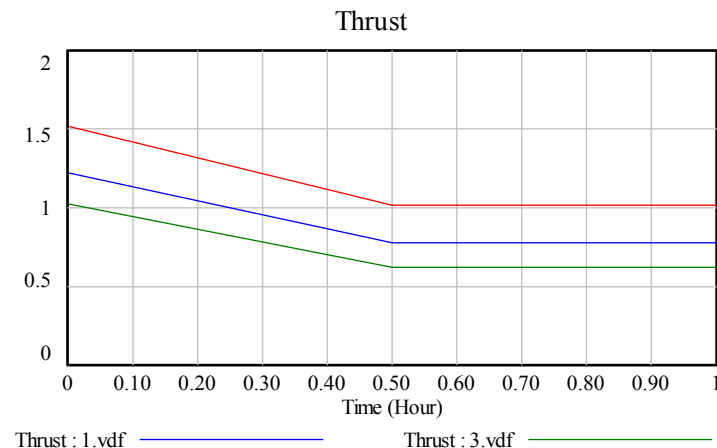

Thrust : 1. vdf

Thrust : $3 . v d f$

Figure 6. Trust with different parameters

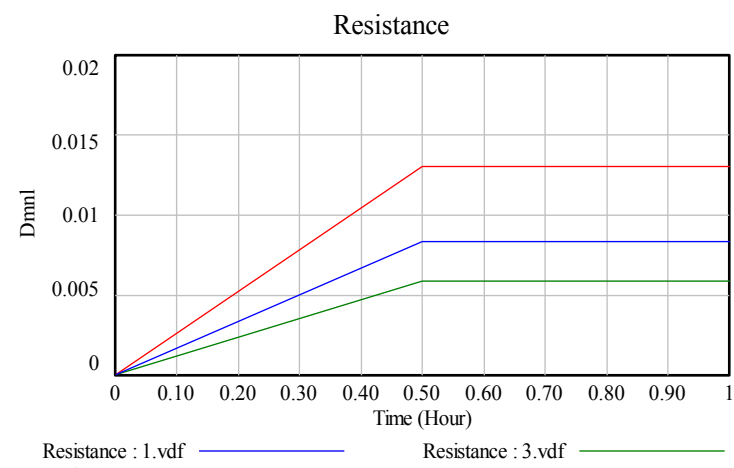

Resistance : 1.vdf

Resistance : $3 . v d f$

Figure 7. Resistance with different parameters

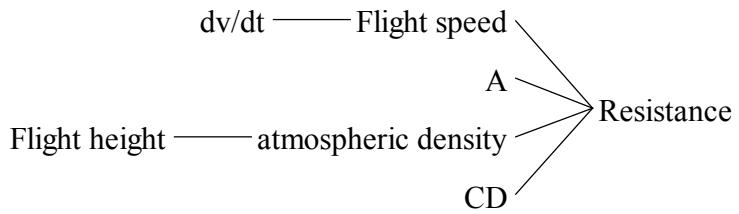

Figure 8. Cause tree for Resistance

Fig .8 gives the cause tree for variable 'Resistance'. From this figure, the proximate causes for Resistance can be easy recognized.

\section{CONCLUSION}

In this paper, a system dynamics evaluation model has been built based on the operating mechanism of the avionic fuel control system for an aircraft. Vensim tool is utilized to model, test and simulate the avionic fuel control process, and to get the variation trends of the variables related to primary design and manufacturing transformation process, follow-up system modification and upgrade process, and even maintenance process. From the related variation trends, the management of avionic fuel system must not only seek for the optimization of strategy, technique, knowledge, operation flow, and human resource, but also coordinate the relation of different components by identifying, assessing, and controlling system risks. Based on these simulations, the risk can be controlled, relieved or even eliminated on the whole.

\section{ACKNOWLEDGMENT}

This work was supported by the project 973 (Grant No. 2014CB744904), the National Science Foundation of China (Grant No. 61179044), the Civil Aviation University of China (CAUC) Research Enabling Foundation (Grant No.2012QD22X), the Fund of National Engineering and Research Center for Commercial Aircraft Manufacturing (Project No.SAMC13-JS-15-016), the Key Project of Tianjin Key Technology R\&D Program (Grant No. 11ZCKFGX04000), the Fundamental Research Funds for the Central Universities (Grant No.3122014C010).

\section{REFERENCES}

[1] Carlos C. Insaurralde, Miguel A. Seminario, Juan F. Jimenez, and Jose M. Giron-Sierra. Computer Tool With a Code Generator for Avionic Distributed Fuel Control Systems With Smart Sensors and Actuators [J], IEEE TRANSACTIONS ON SYSTEMS, MAN, AND CYBERNETICS-PART C: APPLICATIONS AND REVIEWS, 2008, 38(3): 431-445.

[2] Fu Juan, Ma Xian-Min. Research on Fuel Injection Intelligent Control System [C], ICIEA 2009, 2009, 2782-2785.

[3] Zhang Chuntang, Wang Shaokun. System Design For Aircraft Fue Control And Maintenance Test-bed [C], 2014 26th Chinese Control and Decision Conference (CCDC), 2014, 3478-3481.

[4] Hao Long, Shujie Song. A Design of Integrated Aircraft Fuel Control System [C], 2009, 333-336.

[5] Xianling Liao, Xiuli Li, Bingxuan Zhang. System dynamics modeling and simulation of China's SO2 emission trading policy [C], 2011 International conference on computer distributed control and intelligent environmental monitoring, 2011, 280-283.

[6] M. Montazeri-Gh, H. Yousefpour, and S. Jafari. Fuzzy Logic Computing for Design of Gas Turbine Engine Fuel Control System [C], 2010, 5: 723-727.

[7] Ji Li. Reasearch on Modeling and Simulation for fuel regulator of X6 Aero-Engine [D], Northwestern Polytechnical University, Shanxi, Xi'an, 2006.

[8] Erma Suryani, Shuo-Yan Chou, Chih-Hsien Chen. Air passenger demand forecasting and passenger terminal capacity expansion: A system dynamics frame work. Expert Systems with Applications [J], 2010, 37(3): 2324-2339.

[9] Daniel H. Kim. Guidelines for Drawing Causal Loop Diagrams [J], The Systems Thinker, 1992, 3(1): 5-6.

[10] G. P. Richardson and A. L. Pugh, Introduction to system dynamics modeling with DYNAMO, Cambridge MA: Productivity, 1981 